\title{
Elevated serum interleukin-27 levels in patients with systemic sclerosis: association with T cell, B cell and fibroblast activation
}

\author{
Ayumi Yoshizaki, ${ }^{1}$ Koichi Yanaba, ${ }^{1}$ Yohei Iwata, ${ }^{1}$ Kazuhiro Komura, ${ }^{2}$ Asako Ogawa, ${ }^{1}$ \\ Eiji Muroi, ${ }^{1}$ Fumihide Ogawa, ${ }^{1}$ Motoi Takenaka, ${ }^{1}$ Kazuhiro Shimizu, ${ }^{1}$ Minoru Hasegawa, ${ }^{2}$ \\ Manabu Fujimoto, ${ }^{2}$ Shinichi Sato 1,3
}

${ }^{1}$ Department of Dermatology, Nagasaki University Graduate School of Biomedical Sciences, Nagasaki, Japan

${ }^{2}$ Department of Dermatology, Kanazawa University Graduate School of Medical Science, Kanazawa, Japan

${ }^{3}$ Department of Dermatology, The University of Tokyo Graduate School of Medicine, Tokyo, Japan

\section{Correspondence to}

Dr Shinichi Sato, Department of Dermatology, The University of Tokyo Graduate School of Medicine, 7-3-1 Hongo, Bunkyo-ku, Tokyo 113-8655, Japan;

satos-der@h.u-tokyo.ac.jp

Accepted 10 July 2010 Published Online First 12 August 2010

\begin{abstract}
Objective To determine serum levels of interleukin 27 (IL-27) in patients with systemic sclerosis (SSc) and relate the results to the clinical features of SSc.

Methods Serum levels of IL-27 in 91 patients with SSc and the production of IL-27 by isolated monocytes were examined by ELISA. The expression of IL-27 receptor in the skin fibroblasts, B cells and T cells was quantified by real-time PCR. The effect of IL-27 on immunoglobulin G (lgG) production of B cells, IL-17 production of CD4 T cells and proliferation and collagen synthesis of fibroblasts was also analysed.
\end{abstract}

Results Serum IL-27 levels were raised in patients with SSc compared with healthy controls and correlated positively with the extent of skin and pulmonary fibrosis and immunological abnormalities. IL-27 levels also correlated positively with serum levels of hyaluronan, recently identified as an endogenous ligand for Toll-like receptors. The retrospective longitudinal analysis showed a tendency for serum IL-27 levels to be attenuated during the follow-up period. IL-27 production by cultured monocytes was increased by hyaluronan stimulation. IL-27 receptor expression was upregulated in the affected skin fibroblasts, B cells and CD4 T cells of patients with SSc. Moreover, IL-27 stimulation increased lgG production of B cells, IL-17 production of CD4 T cells and proliferation and collagen synthesis of fibroblasts in patients with SSc compared with those in healthy controls.

Conclusion These results suggest that IL-27 and its signalling in B cells, T cells and fibroblasts contributes to disease development in patients with SSc.

\section{INTRODUCTION}

Systemic sclerosis (SSc) is a multisystem disorder of connective tissue characterised by excessive accumulation of extracellular matrix in the skin and various internal organs. ${ }^{1}$ It is accompanied by a number of immunological abnormalities including autoantibody production and elevated levels of several cytokines such as tumour necrosis factor (TNF) $\alpha$ and interleukin (IL)-1 $\beta$, IL-4, IL-6, IL-10 and IL-17..$^{2-4}$ Furthermore, previous studies have shown that serum levels of endogenous ligands for Toll-like receptors (TLR) such as hyaluronan are increased in SSc. ${ }^{5-8}$ In our previous study we showed that serum hyaluronan levels are associated with disease severity and immunological abnormalities. ${ }^{5}$ Although these abnormalities were associated with skin fibrosis and involvement of several organs, the mechanism and pathogenesis of SSc remain unknown. ${ }^{9}$
IL-27 is a new member of the IL-12 and IL-6 families which consists of an IL-12 p40-related protein and a newly discovered IL-12 p35-related protein. ${ }^{10}$ Examination of cDNA libraries has indicated that human IL-27 is highly induced in activated antigen-presenting cells such as monocytes. ${ }^{11-13}$ Although there are no studies of the regulation of IL-27 expression, signalling via TLR4 activated by lipopolysaccharide (LPS) is the key inducer of IL-27.14-16 IL-27 receptor complex comprises IL-27R (also called WSX-1) and glycoprotein 130 (gp130). ${ }^{10} \mathrm{IL}-27$ is the only known ligand for IL-27R. IL-27R and gp130 were found to be coexpressed by a large variety of cells including monocytes, $\mathrm{T}$ cells, B cells and fibroblasts, indicating that IL-27 may display pleiotropic functions. ${ }^{17}$

Previous studies have shown that the role of IL-27 in the regulation of immune responses is somewhat controversial. Some studies have shown that IL-27 promotes naive $T$ cell proliferation and initiates Th1 immune responses. ${ }^{11} 18$ However, other studies have shown that IL-27 suppresses the expansion of effector and memory $\mathrm{T}$ cells and inhibits different cytokine secretion, suggesting anti-inflammatory functions of IL-27. 1920 The dual role of IL-27 in vitro has also been demonstrated on in vivo infectious and autoimmune inflammatory models. IL-27 neutralisation suppressed inflammation in rodent adjuvant arthritis. ${ }^{21}$ In contrast, IL-27R knockout mice displayed deterioration of inflammation in autoimmune encephalomyelitis models. ${ }^{20} 22$ However, at present, our understanding of the role of IL-27 in SSc is limited. The objective of this study is therefore to assess the role of IL-27 in SSc.

\section{PATIENTS AND METHODS}

\section{Serum samples}

Serum samples were obtained from 91 Japanese patients with SSc (81 women and 10 men) at the time of diagnosis. All patients fulfilled the criteria proposed by the American College of Rheumatology. ${ }^{23}$ The duration of the disease was calculated from the time of onset of the first clinical event (other than Raynaud's phenomenon) that was a clear manifestation of SSc. ${ }^{24-26}$ Patients were grouped according to the classification system proposed by LeRoy et a ${ }^{27}$ : 46 patients (44 women and 2 men) had limited cutaneous SSc (ISSc) and 45 patients (37 women 
and 8 men) had diffuse cutaneous SSc (dSSc). The mean \pm SD age of the patients was $47 \pm 16$ years (dSSc; $48 \pm 18$, 1 SSc; $45 \pm 17$ ) and the disease duration of patients with dSSc and $1 S S c$ was $8.5 \pm 9.5$ and $3.1 \pm 2.5$ years, respectively. None of the patients was treated with corticosteroid or other immunosuppressive therapy at the evaluation. Antinuclear antibody (Ab) was determined by indirect immunofluorescence using HEp-2 cells and specificities were further assessed by ELISA and immunoprecipitation. Anti-topoisomerase I Ab was positive for 41 (34 $\mathrm{dSSc}$ and $7 \mathrm{1SSc}$ ), anticentromere $\mathrm{Ab}$ for 37 (2 dSSc and 35 1SSc), anti-U1RNP Ab for 2 (all 1SSc), anti-U3RNP Ab for 1 (dSSc), anti-RNA polymerases I and III Ab for 7 (all dSSc) and Th/To Ab for 1 (ISSc). The remaining two patients were negative for autoantibodies. Twenty age- and sex-matched healthy Japanese individuals (17 women and 3 men; age $48 \pm 15$ years) were used as normal controls. In a retrospective longitudinal analysis we examined serum samples from 10 patients with $\mathrm{SSc}$ (5 dSSc and 5 1SSc).

\section{Clinical assessment}

Complete medical histories, physical examinations and laboratory tests including vital capacity (VC) and diffusion capacity for carbon monoxide (Dlco) were conducted for all patients. When the Dlco and VC were $<75 \%$ and $<80 \%$, respectively, of the predicted normal values, they were considered to be abnormal. Skin score was measured by the modified Rodnan total skin thickness score (TSS). ${ }^{28}$ Organ involvement was defined by rheumatologists, neurologists, nephrologists and radiologists as described previously ${ }^{24-26}$ : pulmonary fibrosis=bibasilar fibrosis on chest radiography and high-resolution CT; oesophagus=hypomotility shown by barium radiography; joints=inflammatory polyarthralgias or arthritis; heart=pericarditis, congestive heart failure or arrhythmias requiring treatment; kidney=malignant hypertension and rapidly progressive renal failure with no other explanation; muscle=proximal muscle weakness and elevated serum creatine kinase.

\section{IL-27R expression in sclerotic skin}

Immunohistochemistry for IL-27R was performed as previously described. ${ }^{29}$ Skin tissues were obtained from the forearms of 10 patients with dSSc ( 5 women and 5 men; median age 42 years, range 28-53) and 5 normal controls. Sections were incubated with a primary monoclonal $\mathrm{Ab}$ to human IL-27R (10 $\mathrm{g} / \mathrm{ml}$; Abcam, Cambridge, Massachusetts, USA). Concentration matched monoclonal mouse immunoglobulin $\mathrm{G}$ (IgG) (Abcam) was used as isotype control staining. The reaction products were visualised using diaminobenzidine (Dako, Carpinteria, California, USA) with methyl green as a counterstain. Each section was examined independently by two investigators (AY and SS) in a blinded manner. Expression levels of IL-27R and IL-27 were also analysed using a real-time PCR quantification method as described previously. ${ }^{6}$ Each sample was tested in duplicate.

\section{ELISAs for serum IL-27, interferon $\gamma$, IL-4, IL-10, IL-17 and hyaluronan levels}

ELISAs for serum levels of IL-27 (ID Labs, London, Ontario, Canada), interferon $\gamma(\mathrm{R} \& \mathrm{D}$ Systems, Minneapolis, Minnesota, USA), IL-4 (R\&D Systems), IL-10 (Immunotech, Munster, Germany), IL-17 (BioSource, Fleurus, Belgium) and hyaluronan (Echelon Biosciences, Salt Lake City, Utah, USA) were performed as described using specific ELISAs. ${ }^{4} 3031$ Each sample was tested in duplicate.

\section{Monocyte, T cell and B cell purification and stimulation}

Heparinised blood samples were obtained from 25 patients with dSSc (21 women and 4 men; median age 47 years, range 21-68) and 10 healthy individuals. Peripheral blood monocytes, CD4 $\mathrm{T}$ cells or B cells were enriched with each isolation kit using AutoMACS isolator (Miltenyi Biotec, Bergisch Gladbach, Germany), respectively. A total of $>99 \%$ of these cells were CD14, CD4 or CD19 (data not shown). To analyse mRNA expression of IL-27R, total RNA was isolated from CD4 T cells and B cells with RNeasy spin columns (Qiagen, Crawley, UK). Purified monocytes, CD4 T cells or B cells $\left(1 \times 10^{5}\right.$, respectively) were cultured in RPMI 1640 containing 10\% heat-inactivated fetal calf serum (Gibco Life Technologies, Paisley, UK). Cells were serum-starved for $12 \mathrm{~h}$ and then stimulated with $0.2 \mathrm{ng} / \mathrm{ml}$ human recombinant IL-27 (rIL-27; R\&D Systems) with or without $50 \mathrm{ng} / \mathrm{ml}$ low molecular weight hyaluronan $(15-40 \mathrm{kDa}$; R\&D Systems) or LPS (Sigma-Aldrich, St Louis, Missouri, USA). rIL-27, hyaluronan and LPS were dissolved in phosphatebuffered saline (PBS). Monocytes or T cells were cultured for $72 \mathrm{~h}$ and IL-27 or IL-17 concentrations in the culture medium were measured by ELISA. In addition, B cells were cultured for 8 days and $\operatorname{IgG}$ concentrations in the culture medium were measured by ELISA (Bethyl Laboratories, Montgomery, Texas, USA). Each sample was performed in triplicate.

\section{Fibroblast proliferation and collagen synthesis with IL-27 stimulation}

Human dermal fibroblasts were obtained by skin biopsy from the forearms of six patients with dSSc ( 3 women and 3 men; median age 41 years, range $28-53$ ) and six healthy individuals. Primary explant cultures were established. ${ }^{32}$ Fibroblasts were serumstarved for $12 \mathrm{~h}$ and then cultured for $24 \mathrm{~h}$ with or without rIL-27 (0.2 ng/ml) and/or rIL-17 (0.2 ng/ml; R\&D Systems). Expression of IL-27R was analysed using western blot assay. ${ }^{33}$ The protein was subjected to sodium dodecyl sulphate-polyacrylamide gel electrophoresis and transferred onto membranes for immunoblotting. These membranes were incubated for $1 \mathrm{~h}$ at room temperature with 1:200 dilutions of the anti-IL-27R Ab (Santa Cruz Biotechnology, Santa Cruz, California, USA). We processed anti-glyceraldehyde 3-phosphate dehydrogenase (GAPDH) Ab (Cell Signaling Technology, Beverly, Massachusetts, USA) as an indicator of the amounts of protein loaded. The intensities of IL-27R band and GAPDH band in each lane were quantified with an automated gel digitising system (Un-Scan-It; Silk Scientific, Orem, Utah, USA). Proliferation of cultured dermal fibroblasts was quantified by a colorimetric 5-bromo-2-deoxyuridine (BrdU) cell proliferation ELISA kit (Roche Applied Science, Indianapolis, Indiana, USA). Type I collagen, the major fibre-forming collagen of the skin, is the product of the proa1 (I) collagen type I $\alpha 1$ (COL1A1) and pro 2 (I) collagen (COL1A2) genes. ${ }^{34}$ Therefore, to assess the collagen synthesis activity in fibroblasts, COL1A1 and COL1A2 were analysed using real-time PCR. Type 1 collagen protein levels were also assessed using a specific ELISA kit (Applied Cell Biotechnologies, Yokohama, Japan). Each sample was performed in triplicate.

\section{Statistical analysis}

The Statview III program (Abacus Concepts, Berkeley, California, USA) was used for statistical analyses. Statistical analysis was performed using the Mann-Whitney $U$ test for determining the level of significance of differences between sample means, the Fisher exact probability test for comparison of frequencies and the Bonferroni test for multiple comparisons. Spearman rank 
correlation coefficient was used to examine the relationship between two continuous variables. A p value $<0.05$ was considered statistically significant.

\section{RESULTS}

\section{Serum IL-27 levels in SSc}

The levels of IL-27 in serum samples from patients with SSc and controls were assessed by ELISA (figure 1). Serum IL-27 levels were significantly elevated in patients with SSc (median $74.1 \mathrm{pg} /$ $\mathrm{ml}$ (range 21.5-188.8)) compared with controls (median $41.8 \mathrm{pg} /$ $\mathrm{ml}$ (range 28.7-63.6); $\mathrm{p}<0.005$ ). For the SSc subgroups, IL-27 levels in both patients with dSSc (median $83.0 \mathrm{pg} / \mathrm{ml}$ (range 37.1-188.8)) and those with 1SSc (median $65.3 \mathrm{pg} / \mathrm{ml}$ (range 21.5-112.1)) were elevated compared with those in controls $(p<0.001$ and $p<0.01$, respectively). Furthermore, serum IL-27 levels were significantly elevated in patients with dSSc relative to those with 1SSc $(p<0.05)$. Values higher than the mean $+2 S D$ $(62.9 \mathrm{pg} / \mathrm{ml})$ of the control serum samples were found in $58 \%$ (53/91) of all patients with SSc, in 71\% (32/45) of patients with $\mathrm{dSSc}$ and in $46 \%(21 / 46)$ of patients with $1 \mathrm{SSc}$. By contrast, only $5 \%(1 / 20)$ of controls had elevated IL-27 levels.

\section{Clinical features of patients with SSc with IL-27 overproduction} We assessed the clinical features of patients with SSc with increased IL-27 production compared with patients with SSc with normal IL-27 production (table 1). The duration of disease

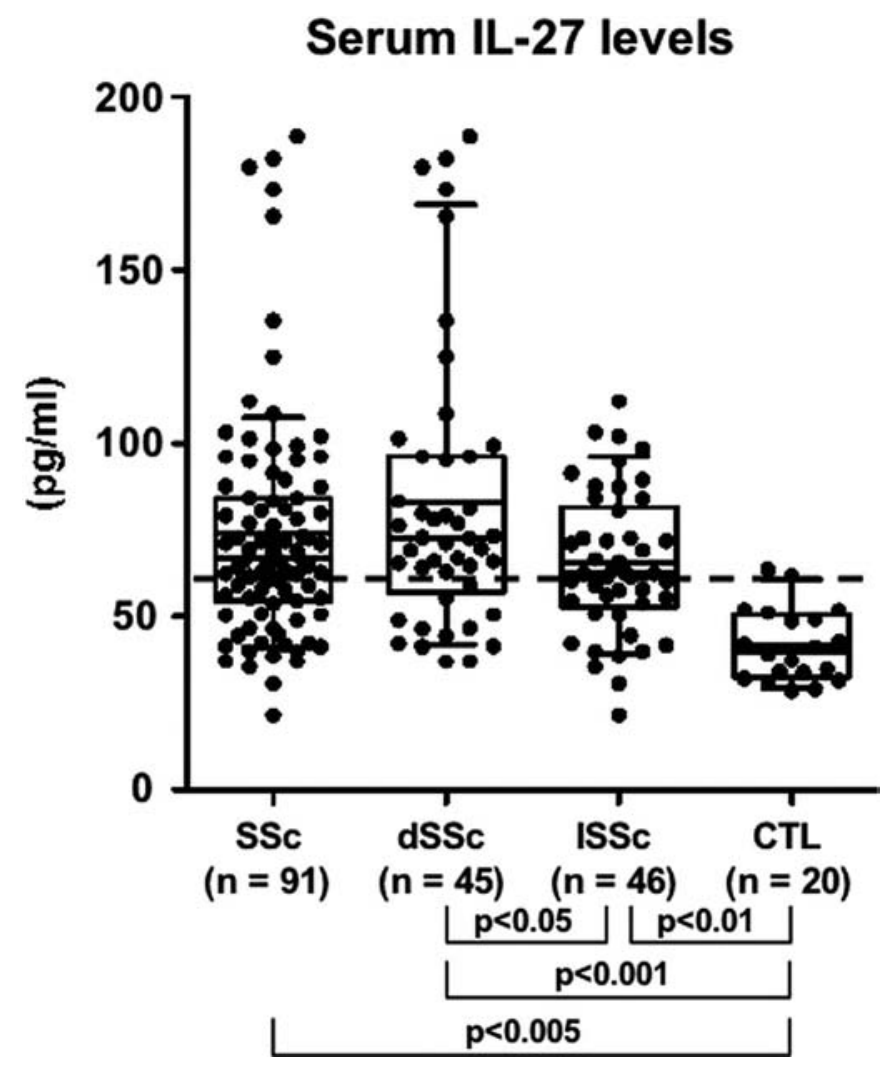

Figure 1 Serum levels of interleukin 27 (IL-27) in patients with systemic sclerosis (SSc), diffuse cutaneous SSc (dSSc) or limited cutaneous SSc (ISSc) and healthy controls (CTL). Serum IL-27 levels were determined by a specific ELISA. Data are presented as box plots, where the lines inside the boxes indicate the medians, the boxes represent the 25th and 75th percentiles and the lines outside the boxes represent the 10th and 90th percentiles. Broken line indicates the cut-off value (mean $+2 S D$ of healthy control samples). was significantly shorter $(\mathrm{p}<0.01)$ in patients with SSc with increased IL-27 production (3.0 \pm 3.2 years, $n=52)$ than in those with normal IL-27 production (7.2 \pm 8.1 years, $n=39)$. Moreover, the retrospective longitudinal analysis in this study showed a tendency for serum IL-27 levels to be attenuated during the follow-up period (figure 2).

In addition, as shown in table 1, patients with SSc with elevated serum levels of IL-27 had significantly higher modified Rodnan TSS points (total SSc, $\mathrm{p}<0.05$; dSSc, $\mathrm{p}<0.01$; 1SSc,

Table 1 Clinical and laboratory features of patients with SSc

\begin{tabular}{|c|c|c|}
\hline Characteristic & $\begin{array}{l}\text { Elevated IL-27 } \\
(n=52)\end{array}$ & $\begin{array}{l}\text { Normal IL-27 } \\
(\mathrm{n}=39)\end{array}$ \\
\hline Sex, M/F & $6 / 46$ & $4 / 35$ \\
\hline Age at onset, mean $\pm S D$ (years) & $47 \pm 14$ & $46 \pm 17$ \\
\hline Disease duration, mean $\pm \mathrm{SD}$ (years) & $3.0 \pm 3.2^{* *}$ & $7.2 \pm 8.1$ \\
\hline Disease pattern, number with dSSc/ISSc & $32 / 20^{*}$ & $13 / 26$ \\
\hline \multicolumn{3}{|l|}{ Clinical features } \\
\hline Modified Rodnan TSS, mean \pm SD (points) & $16.9 \pm 11.2^{*}$ & $11.9 \pm 8.6$ \\
\hline Pitting scar/ulcer & 60 & 41 \\
\hline \multicolumn{3}{|l|}{ Organ involvement } \\
\hline \multicolumn{3}{|l|}{ Lungs } \\
\hline Pulmonary fibrosis & $67^{* *}$ & 31 \\
\hline$\% \mathrm{VC}$, mean $\pm \mathrm{SD}$ & $85.1 \pm 23.4^{*}$ & $97.6 \pm 22.3$ \\
\hline$\%$ Dlco, mean \pm SD & $56.5 \pm 17.6^{*}$ & $66.7 \pm 18.2$ \\
\hline Oesophagus & 63 & 62 \\
\hline Heart & 21 & 15 \\
\hline Kidneys & 4 & 5 \\
\hline Joints & 23 & 15 \\
\hline Muscles & 21 & 15 \\
\hline \multicolumn{3}{|l|}{ Laboratory findings } \\
\hline Serum lgG, mean $\pm S D(m g / d l)$ & $1847 \pm 539 *$ & $1604 \pm 428$ \\
\hline Serum lgM, mean $\pm S D(m g / d l)$ & $197 \pm 125$ & $182 \pm 74$ \\
\hline $\mathrm{CRP}$, mean $\pm \mathrm{SD}(\mathrm{mg} / \mathrm{dl})$ & $0.27 \pm 0.38$ & $0.21 \pm 0.17$ \\
\hline Serum hyaluronan, mean $\pm S D(\mathrm{ng} / \mathrm{ml})$ & $283.9 \pm 161.5^{*}$ & $228.7 \pm 129.6$ \\
\hline Serum IFN $\gamma$, mean \pm SD $(p g / m l)$ & $12.7 \pm 3.3$ & $11.9 \pm 2.4$ \\
\hline Serum IL-4, mean \pm SD (pg/ml) & $67.5 \pm 5.9$ & $56.6 \pm 7.8$ \\
\hline Serum IL-10, mean \pm SD $(p g / m l)$ & $42.1 \pm 6.2$ & $45.3 \pm 8.1$ \\
\hline Serum IL-17, mean $\pm S D(p g / m l)$ & $26.9 \pm 8.1^{* *}$ & $14.3 \pm 5.8$ \\
\hline
\end{tabular}

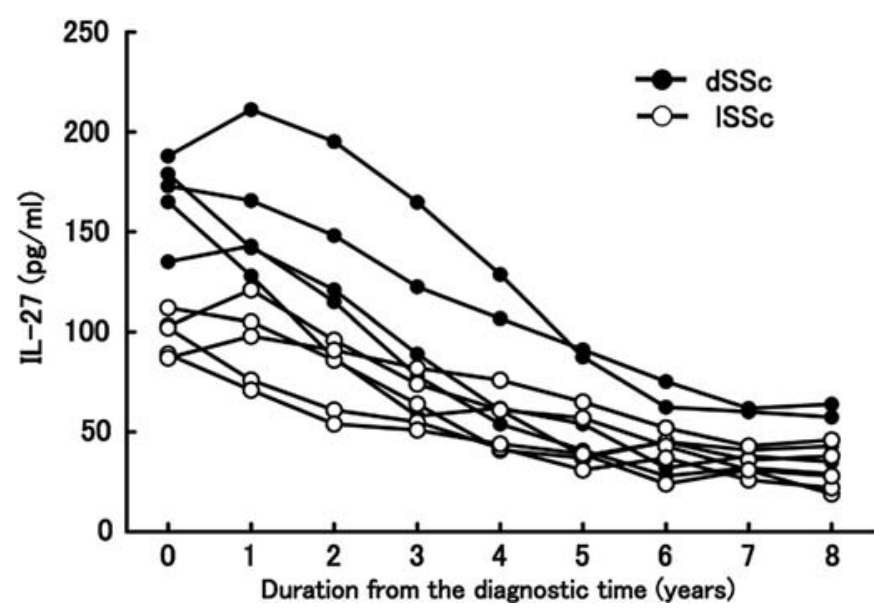

Figure 2 Serial changes in serum interleukin 27 (IL-27) levels during the follow-up period in 10 patients with systemic sclerosis (SSc) patients ( 5 with diffuse cutaneous SSc (dSSc) and 5 with limited cutaneous SSc (ISSc)). This retrospective longitudinal analysis showed the tendency for serum IL-27 levels to be attenuated during the follow-up period. 
$\mathrm{p}<0.05)$, higher frequency of dSSc $(\mathrm{p}<0.01)$, decreased \%VC (total SSc, $\mathrm{p}<0.05$; dSSc, $\mathrm{p}<0.01$; 1SSc, $\mathrm{p}<0.05$ ), decreased \%Dlco (total SSc, $p<0.05$; dSSc, $p<0.01$; 1SSc, $p<0.05$ ), elevated levels of serum hyaluronan (total SSc; $\mathrm{p}<0.05$, dSSc; $\mathrm{p}<0.01,1 \mathrm{SSc}$; $<<0.05$ ) and more frequent involvement of pulmonary fibrosis (total SSc, $\mathrm{p}<0.01$; dSSc, $\mathrm{p}<0.01$; $1 \mathrm{SSc}, \mathrm{p}<0.01)$ than those with normal levels. Serum IL-27 levels also correlated inversely with \%VC (total SSc: $r=-0.29, p<0.005$; dSSc: $r=-0.34, p<0.001$; $1 S S c: r=-0.28$, $p<0.005$ ) or \%Dlco (total SSc: $r=-0.32, p<0.005$; dSSc: $r=-0.36$, $\mathrm{p}<0.001$; 1SSc: $\mathrm{r}=-0.29, \mathrm{p}<0.005$; figure 3$)$. Furthermore, serum IL-27 levels correlated positively with the modified Rodnan TSS (total SSc: $r=0.36, p<0.0005$; dSSc: $r=0.44, p<0.001$; $1 S S c$ : $\mathrm{r}=0.31, \mathrm{p}<0.005$ ) and serum hyaluronan levels (total SSc: $r=0.45$, $\mathrm{p}<0.0001$; dSSc: $\mathrm{r}=0.47, \mathrm{p}<0.0001$; 1SSc: $\mathrm{r}=0.44, \mathrm{p}<0.0001$; figure 3$)$. However, serum IL-27 levels did not correlate with any other clinical parameters.

With regard to correlation of serum IL-27 levels with immunological parameters, patients with SSc with elevated IL-27 levels had significantly higher frequency of elevated levels of serum IgG (total SSc, $\mathrm{p}<0.05$; dSSc, $\mathrm{p}<0.05$; 1SSc, $\mathrm{p}<0.05$ ) and IL-17 (total SSc, $p<0.01$; dSSc, $p<0.01$; 1SSc, $p<0.01$ ) than those with normal levels (table 1). Moreover, serum IL-27 levels correlated positively with levels of serum IgG (total SSc: $r=0.43$, $p<0.0001$; dSSc: $r=0.42, p<0.0001$; 1SSc: $r=0.45, p<0.0001)$ and IL-17 (total SSc: $r=0.39, p<0.0005$; dSSc: $r=0.41, p<0.0001$; 1SSc: $\mathrm{r}=0.35, \mathrm{p}<0.0005$; figure 3 ).

\section{IL-27 production by cultured SSc monocytes}

Unstimulated dSSc monocytes produced higher levels of IL-27 relative to normal monocytes ( $p<0.05$, figure $4 \mathrm{~A}$ ). When monocytes were stimulated with LPS or hyaluronan, IL-27 production by both dSSc and normal monocytes was significantly increased $(p<0.05)$. In addition, IL-27 production by LPS- or hyaluronanstimulated dSSc monocytes was higher than those of normal monocytes $(p<0.01)$. Similar results were obtained using 1SSc samples (data not shown). The minimal effective dose of hyaluronan was $50 \mu \mathrm{g} / \mathrm{ml}$.

\section{Effect of IL-27 on SSc T cells and B cells}

The levels of IL-27R expression on dSSc B cells and CD4 T cells were 3.6- and 3.1-fold higher than those observed in healthy controls $(p<0.005$ and $p<0.001$, respectively; figure 4B). In the absence of IL-27, the production of IgG by hyaluronan-treated $\mathrm{dSSc} B$ cells was higher than that of hyaluronan-stimulated healthy B cells $(p<0.005$, figure $4 C)$. Healthy B cells treated with hyaluronan and IL-27 decreased production of IgG compared with those treated with hyaluronan alone $24 \%$ decrease, $\mathrm{p}<0.01)$, while dSSc B cells treated with hyaluronan and IL-27 increased production of IgG compared with those treated with hyaluronan alone ( $31 \%$ increase, $p<0.01$; figure $4 \mathrm{C})$. Similar to IgG production by B cells, IL-27 treatment reduced IL-17 production by hyaluronan-treated healthy CD4 T cells (41\% decrease, $\mathrm{p}<0.01$ ), while dSSc CD4 T cells treated with both hyaluronan and IL-27 increased production of IL-17 (38\% increase, $p<0.01$; figure 4D). Similar results were obtained using 1 SSc samples (data not shown).

\section{IL-27R expression in the fibrotic skin}

IL-27R expression was only faintly detected in the cell membrane and cytoplasm of healthy skin fibroblasts (figure 5A). In contrast, patients with $\mathrm{dSSc}$ had higher membrane and cytoplasmic expression of IL-27R in skin fibroblasts (figure 5A). While IL-27R expression was also detected in keratinocytes, endothelial cells and perivascular infiltrated and/or resident mononuclear cells, the expression levels of IL-27R in these cells were not different between dSSc and normal skin. IL-27R expression in sclerotic skin of patients with 1SSc was similar to that of patients with dSSc (data not shown). Furthermore, IL-27R expression levels of total skin extract were confirmed using the real-time PCR quantification method ( $p<0.05$, figure $5 B)$. We also assessed IL-27 expression levels in skin samples. IL-27 expression levels in patients with dSSc were significantly higher than those in healthy controls $(p<0.01$, figure $5 B)$.

\section{Fibroblast proliferation and collagen synthesis with IL-27 stimulation}

Stimulation of dSSc or healthy fibroblasts with rIL-17 increased expression of IL-27R compared with PBS alone $(p<0.05$, figure 5C). Similarly, stimulation of fibroblasts with a combination of rIL-17 and rIL-27 increased IL-27R expression compared with PBS alone $(p<0.05)$. Furthermore, the expression levels of IL-27R in dSSc fibroblasts treated with both rIL-17 and rIL-27
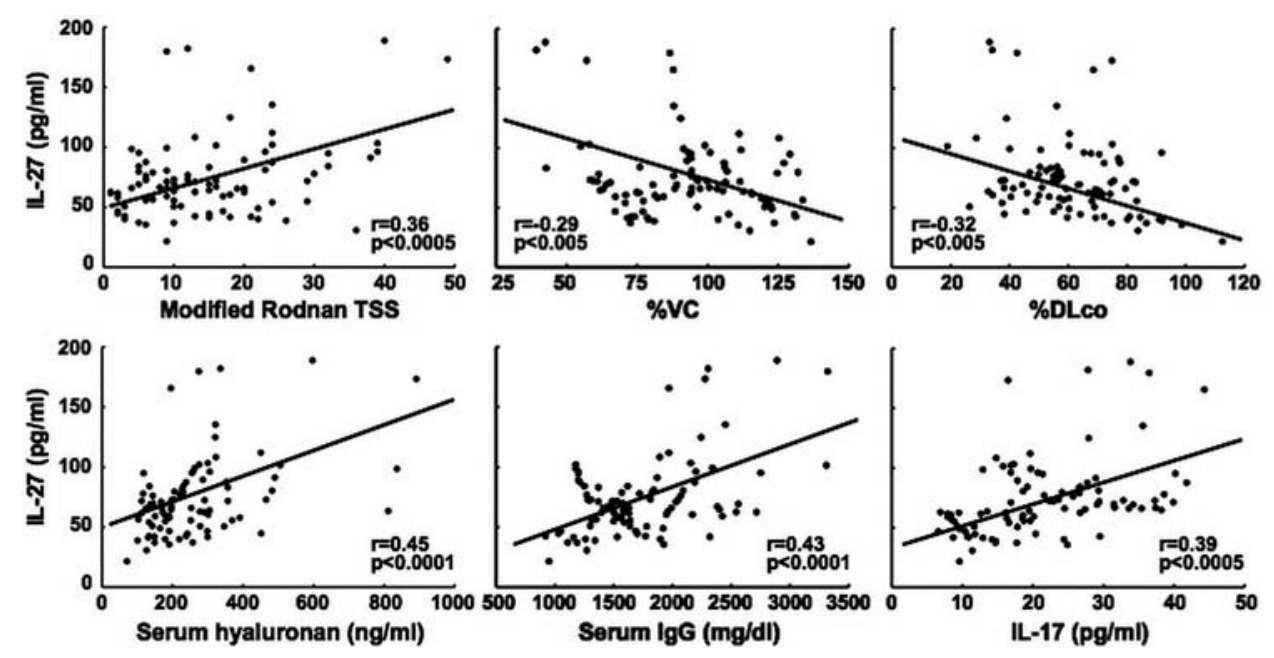

Figure 3 Correlations of serum interleukin 27 (IL-27) levels with modified Rodnan total skin thickness score (TSS), percentage vital capacity (\%VC), percentage diffusion capacity for carbon monoxide (\%Dlco) and serum levels of hyaluronan, IgG and IL-27 in patients with systemic sclerosis. Serum IL-27, hyaluronan and IL-17 levels were determined by specific ELISAs. 

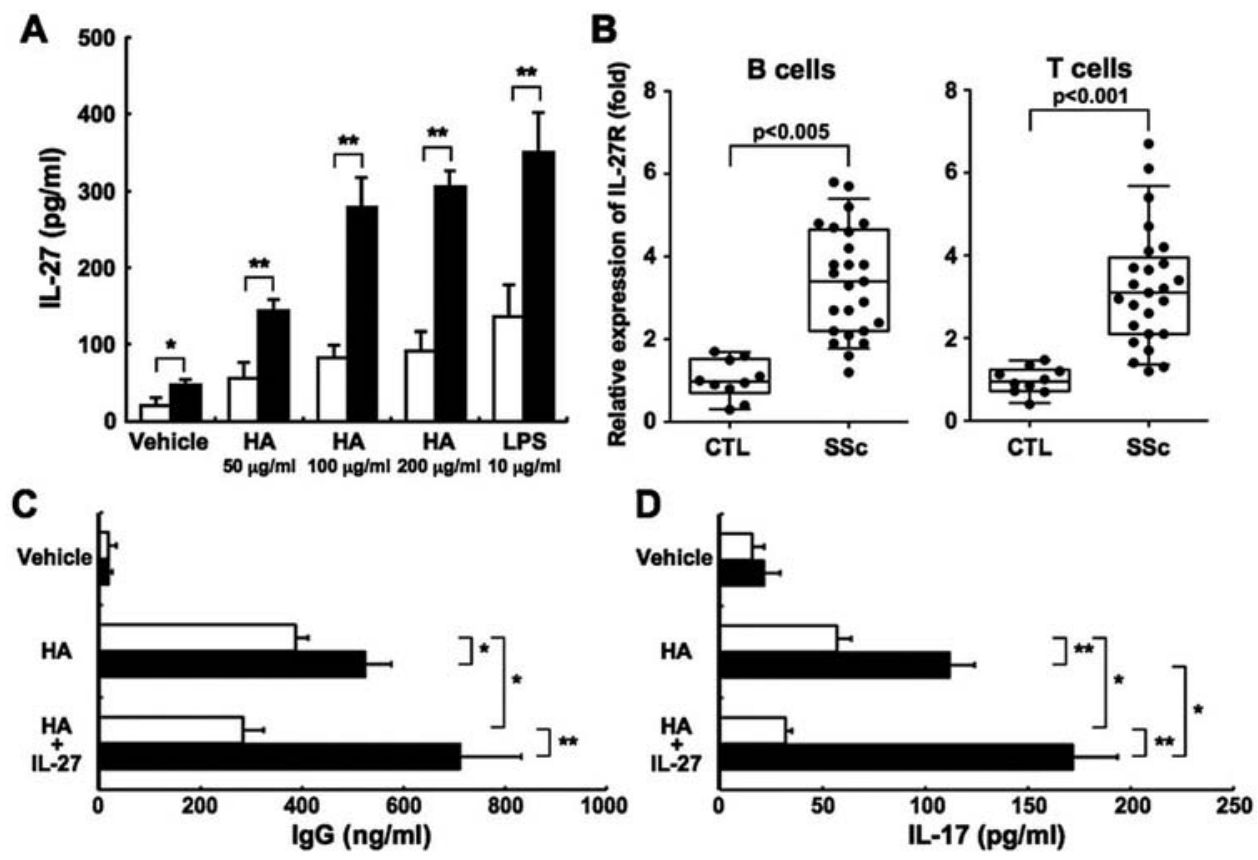

Figure 4 (A) Interleukin 27 (IL-27) production by monocytes, (B) expression of IL-27R on B cells and CD4 T cells and production of (C) IgG and (D) IL-17 by B cells and CD4 T cells, respectively. Monocytes, B cells and CD4 T cells were obtained from peripheral blood of 25 patients with diffuse cutaneous systemic sclerosis (SSc) and 10 healthy controls (CTL). For production of IL-27, purified monocytes $\left(1 \times 10^{5}\right)$ were stimulated with hyaluronan (HA) or lipopolysaccharide (LPS). IL-27R mRNA expression was analysed using real-time PCR. For production of IgG and IL-17, purified $\mathrm{B}$ cells $\left(1 \times 10^{5}\right)$ and CD4 T cells $\left(1 \times 10^{5}\right)$ were stimulated by HA with or without rlL-27. Culture supernatants were analysed by ELISA to determine the amount of IL-27, IgG and IL-17. In (A), (C) and (D), bars show the mean and SD. In (B), the data are presented as box plots where the lines inside the boxes indicate the medians, the boxes represent the 25 th and 75 th percentiles and the lines outside the boxes represent the 10th and 90 th percentiles. ${ }^{*} p<0.01,{ }^{* *} p<0.005$.

were higher than those of rIL-17-treated fibroblasts $(p<0.05)$. However, only rIL-27 stimulation did not affect expression of IL-27R. The levels of IL-27R expression on SSc fibroblasts were higher than those of healthy controls in each group $(p<0.05)$. The proliferative effect of IL-27 was not observed on healthy fibroblasts but was detectable with $0.2 \mathrm{ng} / \mathrm{ml} \mathrm{IL-27} \mathrm{on}$ SSc fibroblasts $(p<0.01$, figure $5 D)$. Similarly, IL-27 had a significant effect on collagen synthesis in fibroblasts. In healthy fibroblasts, $1 \mathrm{ng} / \mathrm{ml}$ IL-27 significantly increased COL1A1 and COL1A2 expression and type I collagen production compared with vehicle alone $(p<0.05)$. In SSc fibroblasts, $0.1 \mathrm{ng} / \mathrm{ml} \mathrm{IL}-27$ also significantly increased COL1A1 and COL1A2 expression and type I collagen production compared with vehicle alone $(p<0.05$, figure 5D).

\section{DISCUSSION}

This study is the first to show that IL-27 levels are elevated in serum samples from patients with SSc compared with normal controls (figure 1). We also showed that IL-27 levels correlated positively with modified Rodnan TSS (figure 3 and table 1). Furthermore, elevation of IL-27 levels was accompanied by the presence of pulmonary fibrosis and decreased $\% \mathrm{VC}$ and \%Dlco, indicating that IL-27 levels correlated with the severity of lung fibrosis. Furthermore, retrospective longitudinal analysis showed that there was a tendency for serum IL-27 levels to be attenuated during the follow-up period (figures 2 and 3 and table 1). Collectively, these results may suggest that overproduction of IL-27 has an important role in the pathogenesis of SSc, especially in the earlier phase of the disease.

IL-27 is mainly secreted from activated antigen-presenting cells such as monocytes by stimulation with their TLR. ${ }^{11-13} 35$
LPS is an exogenous ligand for TLR4 which strongly induces IL-27 secretion from monocytes (figure 4A), as previously described. ${ }^{14}{ }^{15}$ Recently, many studies have identified various endogenous ligands for TLR4, such as hyaluronan which regulates inflammatory responses. ${ }^{6}{ }^{36}$ In our study, hyaluronan treatment enhanced IL-27 production by both healthy and SSc monocytes (figure 4A). Recent studies have shown that, in patients with SSc, monocyte activation may be maintained by one or more enhancing signals such as IL-6 and TNF $\alpha$ which are increased in patients with $\mathrm{SSc}^{37}$ and are known to trigger the activation of TLR4 expression. ${ }^{38}$ This may explain why IL-27 production by SSc monocytes was higher than by healthy monocytes (figure 4A). Thus, IL-27 production is strongly induced by hyaluronan stimulation in SSc monocytes compared with healthy monocytes.

IL-27R is expressed by a wider range of cells, especially activated CD4 $\mathrm{T}$ cells and $\mathrm{B}$ cells, which may explain the pleiotropic role of IL-27. ${ }^{35}$ To date, IL-27R expression in SSc T cells and $\mathrm{B}$ cells remains unknown, although $\mathrm{T}$ cell and $\mathrm{B}$ cell activation is detected in patients with SSc. ${ }^{39}{ }^{40}$ This study is the first to indicate that $\mathrm{T}$ cells and B cells in patients with SSc had higher expression levels of IL-27R than in healthy controls (figure 4B). Currently, the role of IL-27 in various models of inflammatory disease is still controversial. In some disease models such as allergic asthma and experimental autoimmune encephalomyelitis, IL-27 has been found to suppress the inflammation 202241 but, in other disease models such as concanavalin A-induced hepatitis and dextran sulphate sodium- or oxazorolone-induced colitis, IL-27 has been found to exacerbate inflammation. ${ }^{42-44}$ In this study, serum IL-27 levels correlated with serum levels of IgG and IL-17 in patients with SSc (figure 3 and table 1). Furthermore, IL-27 stimulation strongly induced IgG and IL-17 production by 
A
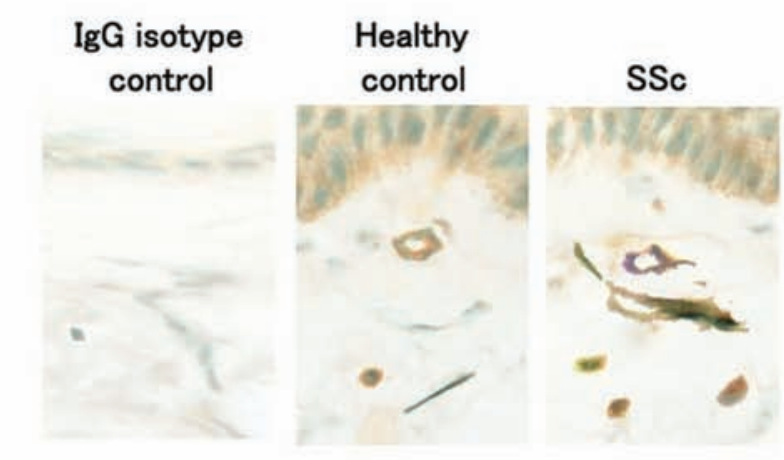

c

PBS IL-27 IL-17 IL-17+IL-27 $\overline{\text { CTL SSc }} \overline{\text { CTL SSc }} \frac{\text { CTL SSc }}{\text { CTL SSc }}$

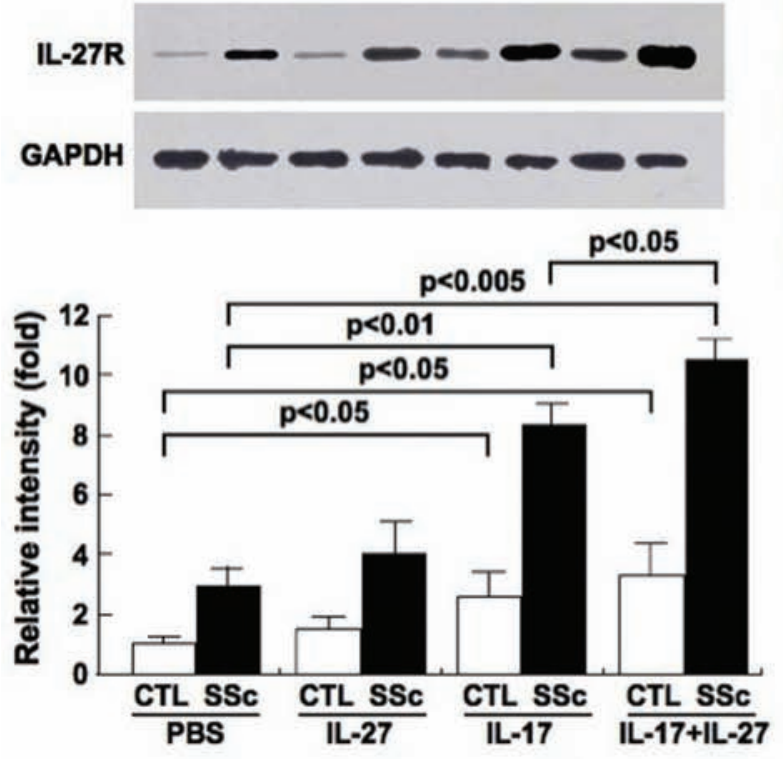

B
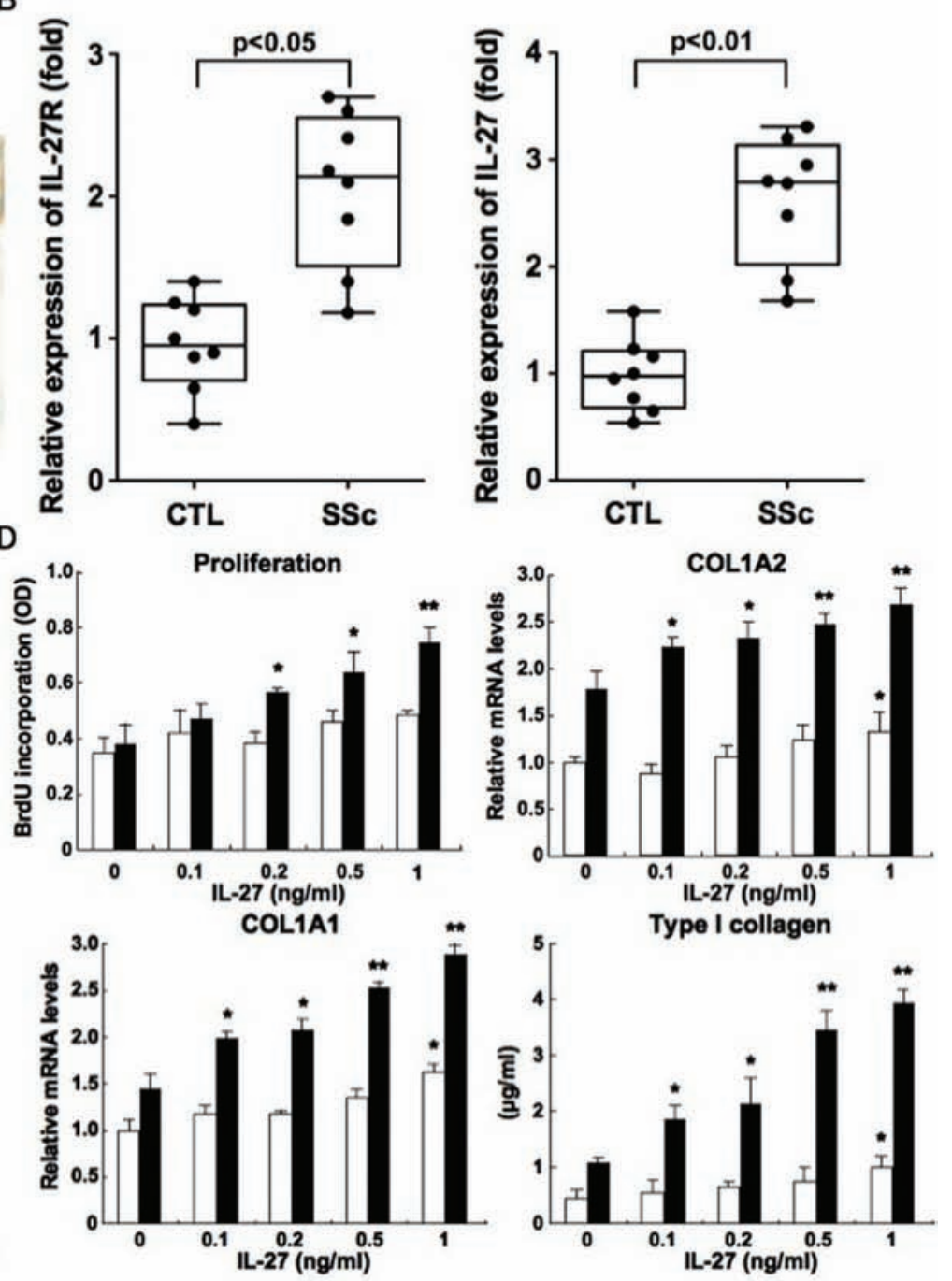

Type I collagen

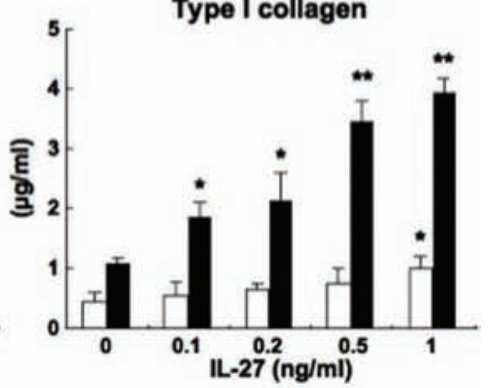

Figure 5 (A) Immunohistochemical analysis of fibrotic skin using interleukin 27 receptor (IL-27R) mouse monoclonal antibody compared with concentration-matched mouse monoclonal antibody lgG isotype control (CTL). (B) IL-27R and IL-27 mRNA expression of healthy control ( $\mathrm{n}=8$ ) and systemic sclerosis (SSc) $(n=8)$ skin analysed using real-time PCR. (C) Western blot analysis of IL-27R protein in stimulated fibroblasts with or without rlL-27 and/or rlL-17. Fibroblasts were grown to confluence and culture medium was replaced with serum-free modified Eagle's medium. (D) After further incubation for $24 \mathrm{~h}$, fibroblasts were stimulated with each concentration of rlL-27 for $24 \mathrm{~h}$. After incubation, collagen type I $\alpha 1$ (COL1A1) and COL1A2 mRNA expression and type I collagen protein production were analysed by real-time PCR and ELISA, respectively. In proliferation assay, after $24 \mathrm{~h}$ incubation, 5-bromo-2-deoxyuridine $(\mathrm{BrdU})(10 \mu \mathrm{m})$ was added to each well and incubated for $24 \mathrm{~h}$. BrdU incorporation in proliferating cells was quantified by ELISA. In (B), data are presented as box plots, where the lines inside the boxes indicate the medians, the boxes represent the 25th and 75 th percentiles and the lines outside the boxes represent the 10th and 90th percentiles. In (C) and (D), bars show the mean and SD. ${ }^{*} p<0.05$, ${ }^{* *} p<0.01$ vs each fibroblast cultured with vehicle alone. Original magnification $\times 100$.

B cells and T cells in patients with SSc (figure 4C,D). Thus, IL-27 may have a role in immunological abnormalities associated with SSc.

A recent study has shown that increased IL-27R expression is also detected in activated fibroblasts. ${ }^{17}$ In our study, IL-27R expression was significantly higher in SSc fibroblasts than in healthy fibroblasts (figure $5 \mathrm{~A}-\mathrm{C}$ ). In patients with SSc, fibroblast activation is induced by several cytokines including IL-17, which may explain the higher expression of IL-27R in SSc fibroblasts. ${ }^{45} 46$ In addition, ligation of IL-27 to IL-27R expressed by fibroblasts is likely to facilitate further fibroblast activation. ${ }^{17}$ Indeed, in this study rIL-17 stimulation increased IL-27R expression on SSc fibroblasts which was further enhanced by rIL-27 costimulation (figure 5B). Furthermore, IL-27 expression was increased in the skin of patients with SSc (figure 5A) and rIL-27 strongly increased proliferation and collagen synthesis of SSc fibroblasts (figure 5D). Thus, IL-27 may have a role in the development of SSc by amplifying collagen synthesis and increasing fibroblast proliferation.

Although further studies are required to clarify the role of IL-27 in the development of SSc, it may be a useful serological marker for disease severity and a new therapeutic target in SSc.

Acknowledgements The authors thank Ms M Yozaki, A Usui and K Shimoda for technical assistance.

Funding This work was supported by a grant for Research on Intractable Diseases from the Ministry of Health, Labour and Welfare of Japan (to AY and SS).

\section{Competing interests None.}

Patient consent Obtained.

Ethics approval This study was conducted with the approval of the Nagasaki University Hospital.

Provenance and peer review Not commissioned; externally peer reviewed. 


\section{REFERENCES}

1. Sato S, Hayakawa I, Hasegawa M, et al. Function blocking autoantibodies agains matrix metalloproteinase-1 in patients with systemic sclerosis. J Invest Dermatol 2003; 120:542-7.

2. La Montagna G, D’Angelo S, Valentini G. Cross-sectional evaluation of YKL-40 serum concentrations in patients with systemic sclerosis. Relationship with clinical and serological aspects of disease. J Rheumato/ 2003;30:2147-51.

3. Szegedi A, Czirják L, Unkeless JC, et al. Serum cytokine and anti-Fc gamma R autoantibody measurements in patients with systemic sclerosis. Acta Derm Venereol 1996; 76:21-3

4. Kurasawa K, Hirose K, Sano H, et al. Increased interleukin-17 production in patients with systemic sclerosis. Arthritis Rheum 2000;43:2455-63.

5. Yoshizaki A, Iwata Y, Komura K, et al. Clinical significance of serum hyaluronan levels in systemic sclerosis: association with disease severity. J Rheumatol 2008;35:1825-9.

6. Yoshizaki A, Iwata $Y$, Komura $K$, et al. CD19 regulates skin and lung fibrosis via toll-like receptor signaling in a model of bleomycin-induced scleroderma. Am J Pathol 2008;172:1650-63

7. Neudecker BA, Stern R, Connolly MK. Aberrant serum hyaluronan and hyaluronidase levels in scleroderma. Br J Dermatol 2004;150:469-76.

8. Levesque H, Baudot N, Delpech B, et al. Clinical correlations and prognosis based on hyaluronic acid serum levels in patients with progressive systemic sclerosis. $\mathrm{Br} \mathrm{J}$ Dermatol 1991;124:423-8.

9. Arnett FC. Is scleroderma an autoantibody mediated disease? Curr Opin Rheumatol 2006;18:579-81.

10. Yoshida H, Miyazaki Y, Yoshiyuki M. Regulation of immune responses by interleukin-27. Immunol Rev 2008;226:234-47.

11. Pflanz S, Timans JC, Cheung J, et al. IL-27, a heterodimeric cytokine composed of EBI3 and p28 protein, induces proliferation of naive $\mathrm{CD} 4(+) \mathrm{T}$ cells. Immunity 2002;16:779-90.

12. Larousserie $\mathbf{F}$, Pflanz S, Coulomb-L'Herminé A, et al. Expression of IL-27 in human Th1-associated granulomatous diseases. J Pathol 2004;202:164-71.

13. Larousserie $\mathbf{F}$, Charlot $\mathrm{P}$, Bardel $\mathrm{E}$, et al. Differential effects of IL-27 on human $B$ cell subsets. J Immunol 2006;176:5890-7.

14. Schuetze N, Schoeneberger S, Mueller U, et al. IL-12 family members: differential kinetics of their TLR4-mediated induction by Salmonella enteritidis and the impact of IL-10 in bone marrow-derived macrophages. Int Immunol 2005; 17:649-59.

15. Schnurr M, Toy T, Shin A, et al. Extracellular nucleotide signaling by P2 receptors inhibits IL-12 and enhances IL-23 expression in human dendritic cells: a novel role for the cAMP pathway. Blood 2005;105:1582-9.

16. Chow JC, Young DW, Golenbock DT, et al. Toll-like receptor-4 mediates lipopolysaccharide-induced signal transduction. J Biol Chem 1999;274:10689-92

17. Pflanz S, Hibbert L, Mattson J, et al. WSX-1 and glycoprotein 130 constitute a signal-transducing receptor for IL-27. J Immunol 2004;172:2225-31.

18. Chen $\mathbf{0}$, Ghilardi N, Wang H, et al. Development of Th1-type immune responses requires the type I cytokine receptor TCCR. Nature 2000;407:916-20.

19. Artis D, Johnson LM, Joyce $K$, et al. Cutting edge: early IL-4 production governs the requirement for IL-27-WSX-1 signaling in the development of protective Th1 cytokine responses following Leishmania major infection. J Immunol 2004;172:4672-5.

20. Batten M, Li J, Yi S, et al. Interleukin 27 limits autoimmune encephalomyelitis by suppressing the development of interleukin 17-producing T cells. Nat Immunol 2006;7:929-36.

21. Goldberg R, Wildbaum G, Zohar Y, et al. Suppression of ongoing adjuvantinduced arthritis by neutralizing the function of the p28 subunit of IL-27. J Immunol 2004;173:1171-8.

22. Stumhofer JS, Laurence A, Wilson EH, et al. Interleukin 27 negatively regulates the development of interleukin 17-producing Thelper cells during chronic inflammation of the central nervous system. Nat Immunol 2006;7:937-45.

23. Subcommittee for Scleroderma Criteria of the American Rheumatism Association Diagnostic and Therapeutic Criteria Committee. Preliminary criteria for the classification of systemic sclerosis (scleroderma). Arthritis Rheum 1980;23:581-90.

24. Sato $\mathbf{S}$, Ihn H, Kikuchi K, et al. Antihistone antibodies in systemic sclerosis. Association with pulmonary fibrosis. Arthritis Rheum 1994;37:391-4.

25. Steen VD, Powell DL, Medsger TA, Jr, Clinical correlations and prognosis based on serum autoantibodies in patients with systemic sclerosis. Arthritis Rheum 1988;31:196-203.

26. Komura K, Sato S, Hasegawa M, et al. Elevated circulating CD40L concentrations in patients with systemic sclerosis. J Rheumatol 2004;31:514-19.

27. LeRoy EC, Black C, Fleischmajer R, et al. Scleroderma (systemic sclerosis) classification, subsets and pathogenesis. J Rheumatol 1988;15:202-5

28. Clements PJ, Lachenbruch PA, Seibold JR, et al. Skin thickness score in systemic sclerosis: an assessment of interobserver variability in 3 independent studies. $J$ Rheumatol 1993;20:1892-6.

29. Seita J, Asakawa M, Ooehara J, et al. Interleukin-27 directly induces differentiation in hematopoietic stem cells. Blood 2008;111:1903-12.

30. Pohjavuori E, Viljanen $M$, Korpela $R$, et al. Lactobacillus GG effect in increasing IFN-gamma production in infants with cow's milk allergy. J Allergy Clin Immunol 2004;114:131-6.

31. Sato S, Hanakawa $\mathrm{H}$, Hasegawa $\mathrm{M}$, et al. Levels of interleukin 12, a cytokine of type 1 helper T cells, are elevated in sera from patients with systemic sclerosis. J Rheumatol 2000;27:2838-42.

32. Iwata $\mathbf{Y}$, Yoshizaki A, Ogawa F, et al. Increased serum pentraxin 3 in patients with systemic sclerosis. J Rheumatol 2009;36:976-83.

33. Hölscher C, Hölscher A, Rückerl D, et al. The IL-27 receptor chain WSX-1 differentially regulates antibacterial immunity and survival during experimental tuberculosis. J Immunol 2005;174:3534-44.

34. Chujo S, Shirasaki F, Kawara S, et al. Connective tissue growth factor causes persistent proalpha2 (I) collagen gene expression induced by transforming growth factor-beta in a mouse fibrosis model. J Cell Physiol 2005;203:447-56.

35. Villarino $\mathbf{A V}$, Huang $\mathrm{E}$, Hunter $\mathrm{CA}$. Understanding the pro- and anti-inflammatory properties of IL-27. J Immunol 2004;173:715-20.

36. Marshak-Rothstein A. Toll-like receptors in systemic autoimmune disease. Nat Rev Immunol 2006;6:823-35.

37. LeRoy EC. Systemic sclerosis. A vascular perspective. Rheum Dis Clin North Am 1996;22:675-94.

38. van Lieshout AW, Vonk MC, Bredie SJ, et al. Enhanced interleukin-10 production by dendritic cells upon stimulation with Toll-like receptor 4 agonists in systemic sclerosis that is possibly implicated in CCL18 secretion. Scand J Rheumatol 2009;38:282-90

39. Sakkas LI, Xu B, Artlett CM, et al. Oligoclonal T cell expansion in the skin of patients with systemic sclerosis. J Immunol 2002;168:3649-59.

40. Sato S, Fujimoto M, Hasegawa M, et al. Altered blood B lymphocyte homeostasis in systemic sclerosis: expanded naive B cells and diminished but activated memory B cells. Arthritis Rheum 2004;50:1918-27.

41. Miyazaki Y, Inoue $H$, Matsumura M, et al. Exacerbation of experimental allergic asthma by augmented Th2 responses in WSX-1-deficient mice. J Immunol 2005;175:2401-7.

42. Siebler J, Wirtz S, Frenzel C, et al. Cutting edge: a key pathogenic role of IL-27 in T cell- mediated hepatitis. J Immunol 2008;180:30-3.

43. Negishi H, Ohba Y, Yanai $\mathrm{H}$, et al. Negative regulation of Toll-like-receptor signaling by IRF-4. Proc Natl Acad Sci USA 2005;102:15989-94.

44. Nieuwenhuis EE, Neurath MF, Corazza N, et al. Disruption of T helper 2-immune responses in Epstein-Barr virus-induced gene 3-deficient mice. Proc Natl Acad Sci USA 2002;99:16951-6.

45. Braun RK, Ferrick C, Neubauer P, et al. IL-17 producing gammadelta T cells are required for a controlled inflammatory response after bleomycin-induced lung injury. Inflammation 2008;31:167-79.

46. Sakkas LI, Chikanza IC, Platsoucas CD. Mechanisms of disease: the role of immune cells in the pathogenesis of systemic sclerosis. Nat Clin Pract Rheumatol 2006;2:679-85. 


\section{ARD}

\section{Elevated serum interleukin-27 levels in patients with systemic sclerosis: association with T cell, B cell and fibroblast activation}

Ayumi Yoshizaki, Koichi Yanaba, Yohei Iwata, et al.

Ann Rheum Dis 2011 70: 194-200 originally published online August 12,2010

doi: 10.1136/ard.2009.121053

Updated information and services can be found at:

http://ard.bmj.com/content/70/1/194.full.html

These include:

References This article cites 46 articles, 20 of which can be accessed free at: http://ard.bmj.com/content/70/1/194.full.htmI\#ref-list-1

Email alerting Receive free email alerts when new articles cite this article. Sign up in service the box at the top right corner of the online article.

Notes

To request permissions go to:

http://group.bmj.com/group/rights-licensing/permissions

To order reprints go to:

http://journals.bmj.com/cgi/reprintform

To subscribe to BMJ go to:

http://group.bmj.com/subscribe/ 